\title{
A Rational Approach to Determining Environmental Noise Indicators
}

\author{
Darko MIHAJLOV*, Momir PRAŠČEVIĆ, Marko LIČANIN, Miomir RAOS, Branko RADIČEVIĆ
}

\begin{abstract}
Environmental noise indicator values that are completely accurate and precise can only be obtained through continuous noise monitoring, which is a highly complex and multifaceted task. In case heavy road traffic is the dominant noise source, accurate and precise data on annual noise indicator values are also obtainable through semicontinuous monitoring. Such a procedure is a rational approach to the given task, as it requires considerably shorter utilization of resources, whereby the primary issue is how to choose the measurement time interval. To help determine the optimal measurement time interval, this paper uses the results of continuous noise monitoring at a selected measurement location as an attempt to minimize the measurement time interval. The choice of the optimal measuring strategy of the problem defined by multiple criteria has been made using the PROMETHEE method, as the most acceptable method for comparing the different alternatives.
\end{abstract}

Keywords: measurement time interval; multi-criteria optimization; noise monitoring; PROMETHEE method; road traffic noise

\section{INTRODUCTION}

A proper insight into the current state of noise in a specific territory, can be gained through strategic noise mapping, which is why it serves as the starting point for defining measures to prevent the increase of noise and to reduce noise emission and immission in the future. Noise maps visually and clearly represent the mechanism of noise propagation from the emission point, as well as the influence of the size, purpose, and spatial position of surrounding structures on noise propagation. In this way, they provide a clear insight into the distribution of "quiet areas", which is highly relevant information for urban spatial planning.

The values of predefined noise indicators, determined using a variety of strategies, are the essential elements for calibrating a strategic noise map, which is a primary document concerning the state of environmental noise. When creating strategic noise maps, it is particularly important to be familiar with the values of equivalent noise level $\left(L_{e q}\right)$ for a given measurement location, whereby the measurement time interval (MTI) is set to one year. Considering the traffic noise fluctuations over a 24 - hour period, which are particularly noticeable between the day and the night periods, and the effect of traffic noise on human activities during those periods, it is necessary to obtain noise level indicators at the selected measurement locations for a one-year period. Specifically, these include the $L_{d e n}$ indicator for 24 hours (day-evening-night) and the separate 8 - hour $L_{\text {night }}$ indicator for the night period, both of which are designated as annual environmental noise indicators by the Directive 2002/49/EC [1].

Since neither the national nor the European legislation do not prescribe any particular means of measuring annual environmental noise indicator values, which are required pieces of data for the calibration of strategic noise maps pursuant to Directive 2002/49/EC, the primary motivation of the present research is to try to find the optimal MTI for determining long-term environmental noise indicator values.

The values of basic noise indicators can be determined in two ways by using either assessment or measurement [24].
Noise assessment (prediction) is performed exclusively through computations using the designated software packages.

Annual noise indicators (ANI) are determined using two measurement methods.

The first method represents a series of short-term measurements of $L_{e q}$, performed in a characteristic noise sources operational regime and within specific metrological parameters. The choice of a time interval for short-term measurement and the number of short-term measurements within the observed time interval of one calendar year are crucial elements for determining the noise indicators at a given location. The MTI for short-term measurement should be at least 10 minutes long, but the 30 - minute interval is recommended to account for the changes in the weather conditions during measurements. The choice of a time interval for short-term measurements is a current topic of interest covered in a number of studies [5], in which researchers opted for different time intervals depending on the number of contributory factors and their contribution to measurement results.

The following method represents a long-term measurement of $L_{e q}$ taking into concern a period that is long enough to include all the changes in the operation of noise sources and weather conditions. Considering the unpredictable behaviour of traffic noise levels over time, the infeasibility to precisely determine the structure and number of vehicles over a specified period, and the connection between the traffic structure and volume and the weather conditions, a sizeable portion of a calendar year is usually taken as the time interval for long-term measurement to determine the noise indicators at a given location. The most common time intervals used are one month, three months, six months, or even the entire calendar year if necessary.

Long-term measurement results are by all means more precise than those of short-term measurement and they can be used with fewer corrections required. Those measurements of $L_{e q}$ should be performed by applying one of the two methods continuous or semicontinuous monitoring.

Continuous monitoring of the traffic noise should be done by utilisation of the real-time measurements of the $L_{e q}$ that are taken at the static measurement position throughout the entire calendar year. This enables observation of the 
realistic noise pattern change at the chosen measurement position, which can be also used in the process of strategic noise maps periodical control.

Semicontinuous method of noise monitoring is usually performed constantly during a period of multiple days or weeks, sometimes even months. This method is also useful for the determination of ANI, when it is necessary to perform environmental noise monitoring in a rational way. The method is particularly useful to determine if noise level boundary limits are being crossed, to inform and educate the community and focus their attention on the current issues, to increase people's knowledge about the noise dose-exposure relationship and the associated effects, and to calibrate noise maps. Semicontinuous monitoring is carried out by noise monitoring stations that can be quickly and easily relocated.

MTIs used in semicontinuous monitoring, as well as a number of measurements at the same position throughout the year, that are sufficient enough to provide representative data for ANI determination, are not defined by existing standards. Having this in mind, researchers chose these parameters in their experimental studies [6] based on existing research conditions such as various noise source regimes, e.g., traffic properties if road traffic is investigated, so that the chosen MTI will be truly representative, meaning that fewer corrections will be required afterwards [7]. When performing the semicontinuous monitoring, the choice of the intervals within a certain season in a calendar year must include all of the situations that are specific for that season (noise change due to the snow, wind, rain, wet road, etc.) [8].

\section{RESEARCH AIM}

The definition of the state of noise level at a specific location is a process involving the identification of dominant noise sources and the monitoring of relevant acoustic and meteorological quantities over a set period at the given location. The most effective approach to the problem is to use long-term, in this case, continuous, annual, noise monitoring at the given location, since strategic noise map, which is a basic document for the analysis of the state of noise, cannot be created without the knowledge of the annual noise burden at the location. However, the complexity of such an approach and its high demands in terms of securing the necessary resources personnel and equipment necessitate resorting to more efficient and rational methods for determining the annual values of $L_{d e n}$ and $L_{\text {night }}$ noise indicators at the location. Such methods should ideally provide values that closely correspond to those obtained through long-term measurement. Accordingly, the aim of this paper is to identify the optimal duration of the MTI. Using a singlerun measurement over an interval significantly shorter than a year, the chosen duration should yield acceptable levels of precision and accuracy in presenting the real state of annual traffic noise level at the given location. This would allow using fewer noise monitoring stations to obtain largescale results that will provide sufficiently precise and accurate data on the annual environmental noise indicator values from multiple measurement locations.

\section{METHODOLOGY}

This study is based on the assumption that long-term continuous monitoring data [9], obtained within a single year, in conjunction with multi-criteria decision making can be used for computation of the optimal MTI. Accuracy of $1,5 \mathrm{~dB}$, as well as precision of $1 \mathrm{~dB}$ criteria, should be met when choosing the optimal time interval for determination of ANI at defined measurement position [10], where road traffic is a primary noise source.

When speaking of accuracy, it means that by using semicontinuous monitoring, the result of ANI measurements will not deviate by more than $1,5 \mathrm{~dB}$ in comparison to the true ANI value obtained by continuous monitoring during the entire year.

The required precision means that, when performing multiple measurements in the same environmental condition at a defined measurement position, using the semicontinuous method, results of standard deviation calculation should not be more than $1 \mathrm{~dB}$.

Values for accuracy and precision are defined based on the requirements for strategic noise map development, which are specified in [1]. Here, it is stated that strategic noise maps should be created using 5 decibel range noise band contours.

The procedure of solving the presented problem is based on multi-criteria decision making, which involves searching for the best solution from a series of allowable solutions in terms of multiple adopted criteria [11].

The problem solution using multi-criteria optimization (MCO) can be divided into four phases [12]:

1.Definition of alternatives and criteria;

2. Assessment of the criteria's relative weights;

3. Adoption of a suitable MCO method;

4. Examination of the chosen alternative reliability.

\subsubsection{Definition of the Set of Alternatives}

According to the established goal of the research, four alternatives have been presented, each containing a different MTI:

- $a_{1}$ - One week

- $a_{2}$ - One month

- $a_{3}$ - Six months

- $a_{4}$ - One year.

The preference for a perfect solution would be the order of alternatives $\left(a_{1} \rightarrow a_{2} \rightarrow a_{3} \rightarrow a_{4}\right)$ where it is preferable to use a minimum of the monitoring station operation while receiving reliable results of ANI value since only one-year-long measurement $\left(a_{4}\right)$ has been shown to provide the accurate value. The main issue of using $a_{4}$ is that equipment has to remain at the same location for the entire year, which minimizes its usability.

\subsubsection{Definition of the Set of Criteria}

In this study, a set of nine criteria is considered for the choice of optimal MTI using multi-criteria decision making (Tab. 1).

Once the alternatives and the criteria have been defined, the mathematical formulation of the MCO problem can be expressed as follows: 
$\operatorname{Max} / \operatorname{Min}\left\{\begin{array}{c}f_{1}(x), f_{2}(x), \ldots, f_{j}(x), \ldots, f_{9}(x) \\ \forall x \in A=\left[a_{1}, a_{2}, a_{3}, a_{4}\right]\end{array}\right\}$

Table 1 Criteria for the selection of the optimal measurement strategy

\begin{tabular}{|c|l|}
\hline Criterion & \multicolumn{1}{c|}{ Criterion name / definition } \\
\hline$f_{1}$ & Standard deviation of value $L_{\text {day }}$ \\
\hline$f_{2}$ & Standard deviation of value $L_{\text {evening }}$ \\
\hline$f_{3}$ & Standard deviation of value $L_{\text {night }}$ \\
\hline$f_{4}$ & Standard deviation of value $L_{\text {den }}$ \\
\hline$f_{5}$ & Maximum deviation of value $L_{\text {day }}$ \\
\hline$f_{6}$ & Maximum deviation of value $L_{\text {evening }}$ \\
\hline$f_{7}$ & Maximum deviation of value $L_{\text {night }}$ \\
\hline$f_{8}$ & Maximum deviation of value $L_{\text {den }}$ \\
\hline$f_{9}$ & Degree of measur. equipment utilization \\
\hline
\end{tabular}

Criteria that have been chosen are separated into categories, where first category criteria $f_{1}-f_{4}$ refer to the standard deviation of measured noise indicators. Deviation has been calculated as an average deviation of a dataset from its mean value, for different observed alternatives. It is important to emphasize that standard deviation, in this case, should not exceed $1 \mathrm{~dB}$, as this is the value that ultimately meets the result precision requirement, which is why a minimization requirement is set for the given criteria. Small values of the standard deviation of the measurement results indicate that there are small deviations from the average value of a noise indicator for a given MTI. This implies that the factors contributing to these indicators vary insignificantly with time at a chosen location.

Criteria $f_{5}-f_{8}$ are denoted as the second category which is related to a maximum difference of each of the noise indicators $\left(L_{\text {day }}, L_{\text {evening }}, L_{\text {night }}\right)$ from their respective value obtained for the entire year. This has been done for all of the measurement alternatives $\left(a_{1}-a_{4}\right)$.

The analysis of the measurement results indicates an increase in accuracy and precision of the results with the increase of the MTI; however, it also indicates a decrease in the degree of utilization of the measuring equipment.

A fundamental task of this research is to determine the interdependence of the given criteria and their influence on the choice of optimal measurement strategy. The goals of the set criteria and the requirements for their extremization (maximization or minimization), as well as the criteria evaluation types, are given inTab. 2.
Table 2 Criteria goal functions and evaluation types

\begin{tabular}{|c|c|c|}
\hline Criterion & Goal/ Requirement & Evaluation type \\
\hline$f_{1}$ & $\min$ & Quantitative \\
\hline$f_{2}$ & $\min$ & Quantitative \\
\hline$f_{3}$ & $\mathrm{~min}$ & Quantitative \\
\hline$f_{4}$ & $\mathrm{~min}$ & Quantitative \\
\hline$f_{5}$ & $\mathrm{~min}$ & Quantitative \\
\hline$f_{6}$ & $\mathrm{~min}$ & Quantitative \\
\hline$f_{7}$ & $\mathrm{~min}$ & Quantitative \\
\hline$f_{8}$ & $\mathrm{~min}$ & Quantitative \\
\hline$f_{9}$ & $\mathrm{max}$ & Qualitative \\
\hline
\end{tabular}

Criterion $f_{9}$ is denoted as a category of a third class. It is related to the analysis of measuring equipment duration of use. Unlike all other criteria, criterion $f_{9}$ is described by its nature as a qualitative feature. For each of the qualitative attributes, there is an assigned quantitative mark. The assignment has been performed using the Saaty scale [13], which is shown in Tab. 3 .

Table 3 Assessment of qualitative features for criterion $f_{9}$ with a goal of criterion set to max, for alternatives $\left(a_{1}-a_{4}\right)$

\begin{tabular}{|c|c|c|}
\hline \multirow{2}{*}{} & \multicolumn{2}{|c|}{ Criteria $f_{9}$} \\
\cline { 2 - 3 } & Goal of criteria: $\max$ \\
\cline { 2 - 3 } & Qualitative mark & Quantitative mark \\
\hline$a_{1}$ & Very good & 9 \\
\hline$a_{2}$ & Average & 2 \\
\hline$a_{3}$ & Fair & 1 \\
\hline$a_{4}$ & Bad & \\
\hline
\end{tabular}

\subsection{Assessment of the Relative Weights of Criteria}

Considering that the set criteria are not equally important, the so-called criteria weights have been defined. This has been done by assigning a factor of significance to each of the criteria. To achieve this goal, a Delphi methodology $[14,15]$ has been taken into account. Also, the proposed criteria weights have been considered by a selected panel of ten experts in the field surveyed for that purpose. An expert who was involved in the data processing was not included in the survey.

Combination of alternatives and criteria, as well as the shape of the decision matrix and the weighting of criteria $w_{j}$, have all been given in Tab. 4 .

Table 4 Alternatives, evaluations, goals, and weight coefficients of criteria for the selection of the optimal alternative

\begin{tabular}{|c|c|c|c|c|c|c|c|c|c|}
\hline & $f_{1}$ & $f_{2}$ & $f_{3}$ & $f_{4}$ & $f_{5}$ & $f_{6}$ & $f_{7}$ & $f_{8}$ & $f_{9}$ \\
\hline$a_{1}$ & $f_{1}\left(a_{1}\right)$ & $f_{2}\left(a_{1}\right)$ & $f_{3}\left(a_{1}\right)$ & $f_{4}\left(a_{1}\right)$ & $f_{5}\left(a_{1}\right)$ & $f_{6}\left(a_{1}\right)$ & $f_{7}\left(a_{1}\right)$ & $f_{8}\left(a_{1}\right)$ & $f_{9}\left(a_{1}\right)$ \\
\hline$a_{2}$ & $f_{1}\left(a_{2}\right)$ & $f_{2}\left(a_{2}\right)$ & $f_{3}\left(a_{2}\right)$ & $f_{4}\left(a_{2}\right)$ & $f_{5}\left(a_{2}\right)$ & $f_{6}\left(a_{2}\right)$ & $f_{7}\left(a_{2}\right)$ & $f_{8}\left(a_{2}\right)$ & $f_{9}\left(a_{2}\right)$ \\
\hline$a_{3}$ & $f_{1}\left(a_{3}\right)$ & $f_{2}\left(a_{3}\right)$ & $f_{3}\left(a_{3}\right)$ & $f_{4}\left(a_{3}\right)$ & $f_{5}\left(a_{3}\right)$ & $f_{6}\left(a_{3}\right)$ & $f_{7}\left(a_{3}\right)$ & $f_{8}\left(a_{3}\right)$ & $f_{9}\left(a_{3}\right)$ \\
\hline$a_{4}$ & $f_{1}\left(a_{4}\right)$ & $f_{2}\left(a_{4}\right)$ & $f_{3}\left(a_{4}\right)$ & $f_{4}\left(a_{4}\right)$ & $f_{5}\left(a_{4}\right)$ & $f_{6}\left(a_{4}\right)$ & $f_{7}\left(a_{4}\right)$ & $f_{8}\left(a_{4}\right)$ & $f_{9}\left(a_{4}\right)$ \\
\hline Goal & $\min$ & $\min$ & $\min$ & $\min$ & $\min$ & $\min$ & $\min$ & $\min$ & $\max$ \\
\hline$w_{j}$ & 0.05 & 0.05 & 0.05 & 0.10 & 0.05 & 0.05 & 0.05 & 0.10 & 0.50 \\
\hline
\end{tabular}

\subsection{Selection of a Multi-Criteria Optimization Method}

The issue of choosing the optimal measurement strategy for a problem defined by multiple criteria can be resolved using the PROMETHEE method [16]. The method is acceptable for its possibility of selecting how the alternatives will be mutually compared. This comparison refers to the features and the value of the explicit criteria by selecting the adequate preference function. PROMETHEE is also suitable for its ability to define important parameters such as preference $(p)$ and indifference $(q)$. These parameters, in combination with weight coefficients, have the most important part in the resolution of the presented issue [17]. By applying this method, the described problem can be solved through the following steps [18]:

$1^{\text {st }}$ Step - Determination of the general criterion shape, as well as $p / q$ for the individual criterion (Tab. 5).

$2^{\text {nd }}$ Step - The determination of a preference function for all alternative pairs according to each criterion in the given 
order. The value of preference function $P_{j}\left(a_{1}, a_{2}\right)$ indicates the preference of the alternative $a_{1}$ over the alternative $a_{2}$ for the $j^{\text {th }}$ criterion (Tab. 6).

Table 5 Shape of general criterion and the p/q parameters for each explicit criterion

\begin{tabular}{|c|c|c|c|c|c|c|c|c|c|}
\hline Criterion & $f_{1}$ & $f_{2}$ & $f_{3}$ & $f_{4}$ & $f_{5}$ & $f_{6}$ & $f_{7}$ & $f_{8}$ & $f_{9}$ \\
\hline Shape of general criterion & III & III & III & III & V & V & V & V & III \\
\hline Preference parameter, $p$ & 2 & 2 & 2 & 2 & 3 & 3 & 3 & 3 & 10 \\
\hline Indifference parameter, $q$ & - & - & - & - & 0.5 & 0.5 & 0.5 & 0.5 & - \\
\hline
\end{tabular}

\begin{tabular}{|c|c|c|c|c|c|c|c|c|c|}
\hline & $f_{1}$ & $f_{2}$ & $f_{3}$ & $f_{4}$ & $f_{5}$ & $f_{6}$ & $f_{7}$ & $f_{8}$ & $f_{0}$ \\
\hline$P_{j}\left(a_{1}, a_{2}\right)$ & $P_{1}\left(a_{1}, a_{2}\right)$ & $P_{2}\left(a_{1}, a_{2}\right)$ & $P_{3}\left(a_{1}, a_{2}\right)$ & $P_{4}\left(a_{1}, a_{2}\right)$ & $P_{5}\left(a_{1}, a_{2}\right)$ & $P_{6}\left(a_{1}, a_{2}\right)$ & $P_{7}\left(a_{1}, a_{2}\right)$ & $P_{8}\left(a_{1}, a_{2}\right)$ & $P_{9}\left(a_{1}, a_{2}\right)$ \\
\hline$P_{j}\left(a_{1}, a_{3}\right)$ & $P_{1}\left(a_{1}, a_{3}\right)$ & $P_{2}\left(a_{1}, a_{3}\right)$ & $P_{3}\left(a_{1}, a_{3}\right)$ & $P_{4}\left(a_{1}, a_{3}\right)$ & $P_{5}\left(a_{1}, a_{3}\right)$ & $P_{6}\left(a_{1}, a_{3}\right)$ & $P_{7}\left(a_{1}, a_{3}\right)$ & $P_{8}\left(a_{1}, a_{3}\right)$ & $P_{9}\left(a_{1}, a_{3}\right)$ \\
\hline$P_{j}\left(a_{1}, a_{4}\right)$ & $P_{1}\left(a_{1}, a_{4}\right)$ & $P_{2}\left(a_{1}, a_{4}\right)$ & $P_{3}\left(a_{1}, a_{4}\right)$ & $P_{4}\left(a_{1}, a_{4}\right)$ & $P_{5}\left(a_{1}, a_{4}\right)$ & $P_{6}\left(a_{1}, a_{4}\right)$ & $P_{7}\left(a_{1}, a_{4}\right)$ & $P_{8}\left(a_{1}, a_{4}\right)$ & $P_{9}\left(a_{1}, a_{4}\right)$ \\
\hline$P_{j}\left(a_{2}, a_{1}\right)$ & $P_{1}\left(a_{2}, a_{1}\right)$ & $P_{2}\left(a_{2}, a_{1}\right)$ & $P_{3}\left(a_{2}, a_{1}\right)$ & $P_{4}\left(a_{2}, a_{1}\right)$ & $P_{5}\left(a_{2}, a_{1}\right)$ & $P_{6}\left(a_{2}, a_{1}\right)$ & $P_{7}\left(a_{2}, a_{1}\right)$ & $P_{8}\left(a_{2}, a_{1}\right)$ & $P_{9}\left(a_{2}, a_{1}\right)$ \\
\hline$P_{j}\left(a_{2}, a_{3}\right)$ & $P_{1}\left(a_{2}, a_{3}\right)$ & $P_{2}\left(a_{2}, a_{3}\right)$ & $P_{3}\left(a_{2}, a_{3}\right)$ & $P_{4}\left(a_{2}, a_{3}\right)$ & $P_{5}\left(a_{2}, a_{3}\right)$ & $P_{6}\left(a_{2}, a_{3}\right)$ & $P_{7}\left(a_{2}, a_{3}\right)$ & $P_{8}\left(a_{2}, a_{3}\right)$ & $P_{9}\left(a_{2}, a_{3}\right)$ \\
\hline$P_{j}\left(a_{2}, a_{4}\right)$ & $P_{1}\left(a_{2}, a_{4}\right)$ & $P_{2}\left(a_{2}, a_{4}\right)$ & $P_{3}\left(a_{2}, a_{4}\right)$ & $P_{4}\left(a_{2}, a_{4}\right)$ & $P_{5}\left(a_{2}, a_{4}\right)$ & $P_{6}\left(a_{2}, a_{4}\right)$ & $P_{7}\left(a_{2}, a_{4}\right)$ & $P_{8}\left(a_{2}, a_{4}\right)$ & $P_{9}\left(a_{2}, a_{4}\right)$ \\
\hline$P_{j}\left(a_{3}, a_{1}\right)$ & $P_{1}\left(a_{3}, a_{1}\right)$ & $P_{2}\left(a_{3}, a_{1}\right)$ & $P_{3}\left(a_{3}, a_{1}\right)$ & $P_{4}\left(a_{3}, a_{1}\right)$ & $P_{5}\left(a_{3}, a_{1}\right)$ & $P_{6}\left(a_{3}, a_{1}\right)$ & $P_{7}\left(a_{3}, a_{1}\right)$ & $P_{8}\left(a_{3}, a_{1}\right)$ & $P_{9}\left(a_{3}, a_{1}\right)$ \\
\hline$P_{j}\left(a_{3}, a_{2}\right)$ & $P_{1}\left(a_{3}, a_{2}\right)$ & $P_{2}\left(a_{3}, a_{2}\right)$ & $P_{3}\left(a_{3}, a_{2}\right)$ & $P_{4}\left(a_{3}, a_{2}\right)$ & $P_{5}\left(a_{3}, a_{2}\right)$ & $P_{6}\left(a_{3}, a_{2}\right)$ & $P_{7}\left(a_{3}, a_{2}\right)$ & $P_{8}\left(a_{3}, a_{2}\right)$ & $P_{9}\left(a_{3}, a_{2}\right)$ \\
\hline$P_{j}\left(a_{3}, a_{4}\right)$ & $P_{1}\left(a_{3}, a_{4}\right)$ & $P_{2}\left(a_{3}, a_{4}\right)$ & $P_{3}\left(a_{3}, a_{4}\right)$ & $P_{4}\left(a_{3}, a_{4}\right)$ & $P_{5}\left(a_{3}, a_{4}\right)$ & $P_{6}\left(a_{3}, a_{4}\right)$ & $P_{7}\left(a_{3}, a_{4}\right)$ & $P_{8}\left(a_{3}, a_{4}\right)$ & $P_{9}\left(a_{3}, a_{4}\right)$ \\
\hline$P_{j}\left(a_{4}, a_{1}\right)$ & $P_{1}\left(a_{4}, a_{1}\right)$ & $P_{2}\left(a_{4}, a_{1}\right)$ & $P_{3}\left(a_{4}, a_{1}\right)$ & $P_{4}\left(a_{4}, a_{1}\right)$ & $P_{5}\left(a_{4}, a_{1}\right)$ & $P_{6}\left(a_{4}, a_{1}\right)$ & $P_{7}\left(a_{4}, a_{1}\right)$ & $P_{8}\left(a_{4}, a_{1}\right)$ & $P_{9}\left(a_{4}, a_{1}\right)$ \\
\hline$P_{j}\left(a_{4}, a_{2}\right)$ & $P_{1}\left(a_{4}, a_{2}\right)$ & $P_{2}\left(a_{4}, a_{2}\right)$ & $P_{3}\left(a_{4}, a_{2}\right)$ & $P_{4}\left(a_{4}, a_{2}\right)$ & $P_{5}\left(a_{4}, a_{2}\right)$ & $P_{6}\left(a_{4}, a_{2}\right)$ & $P_{7}\left(a_{4}, a_{2}\right)$ & $P_{8}\left(a_{4}, a_{2}\right)$ & $P_{9}\left(a_{4}, a_{2}\right)$ \\
\hline$P_{j}\left(a_{4}, a_{3}\right)$ & $P_{1}\left(a_{4}, a_{3}\right)$ & $P_{2}\left(a_{4}, a_{3}\right)$ & $P_{3}\left(a_{4}, a_{3}\right)$ & $P_{4}\left(a_{4}, a_{3}\right)$ & $P_{5}\left(a_{4}, a_{3}\right)$ & $P_{6}\left(a_{4}, a_{3}\right)$ & $P_{7}\left(a_{4}, a_{3}\right)$ & $P_{8}\left(a_{4}, a_{3}\right)$ & $P_{9}\left(a_{4}, a_{3}\right)$ \\
\hline$w_{j}$ & 0.05 & 0.05 & 0.05 & 0.10 & 0.05 & 0.05 & 0.05 & 0.10 & 0.50 \\
\hline
\end{tabular}

$3^{\text {rd }}$ Step - The definition of the preference index for pairs of alternatives according to Eq. (2), as well as the formation of the preference index matrix:

$\pi\left(a_{1}, a_{2}\right)=\frac{\sum_{j=1}^{m}\left[w_{j} \cdot P_{j}\left(a_{1}, a_{2}\right)\right]}{\sum_{j=1}^{m} w_{j}}$

where $w_{j}$ is the criteria weight coefficient, and $P_{j}\left(a_{1}, a_{2}\right)$ is the preference of the alternative $a_{1}$ over the alternative $a_{2}$ for the $j^{\text {th }}$ criterion.

The preference index $\pi\left(a_{1}, a_{2}\right)$ indicates the preference of the alternative $a_{1}$ over the alternative $a_{2}$ while simultaneously taking into account all the criteria. It varies between 0 and 1 (Tab. 7).

Table 7 Value of preference index
\begin{tabular}{|c|c|c|c|c|}
\hline & $a_{1}$ & $a_{2}$ & $a_{3}$ & $a_{4}$ \\
\hline$a_{1}$ & 0 & $\pi\left(a_{1}, a_{2}\right)$ & $\pi\left(a_{1}, a_{3}\right)$ & $\pi\left(a_{1}, a_{4}\right)$ \\
\hline$a_{2}$ & $\pi\left(a_{2}, a_{1}\right)$ & 0 & $\pi\left(a_{2}, a_{3}\right)$ & $\pi\left(a_{2}, a_{4}\right)$ \\
\hline$a_{3}$ & $\pi\left(a_{3}, a_{1}\right)$ & $\pi\left(a_{3}, a_{2}\right)$ & 0 & $\pi\left(a_{3}, a_{4}\right)$ \\
\hline$a_{4}$ & $\pi\left(a_{4}, a_{1}\right)$ & $\pi\left(a_{4}, a_{2}\right)$ & $\pi\left(a_{4}, a_{3}\right)$ & 0 \\
\hline
\end{tabular}

$4^{\text {th }}$ Step - The computation of output and input flow values for each alternative according to Eq. (3) and Eq. (4) below and the establishment of a partial order of the compared alternatives (PROMETHEE 1):

$$
\begin{gathered}
\Phi^{+}\left(a_{i}\right)=\frac{1}{n-1} \sum_{j=1}^{n} \pi\left(a_{i}, f_{j}\right) \\
\Phi^{-}\left(a_{j}\right)=\frac{1}{n-1} \sum_{i=1}^{n} \pi\left(f_{j}, a_{i}\right)
\end{gathered}
$$

The output flow value $\Phi^{+}\left(a_{i}\right)$ shows how much the alternative $a_{1}$ is better than all the other alternatives from the set of alternatives A for all the criteria from the set of criteria C. In contrast, the input flow value $\Phi^{-}\left(a_{i}\right)$ shows how much all the other alternatives are better than the alternative $a_{1}$. The higher the output flow value $\Phi^{+}\left(a_{i}\right)$, the more the alternative $a_{1}$ dominates the other alternatives in the set of alternatives A. The higher the input flow value $\Phi^{-}\left(a_{i}\right)$, the more the other alternatives dominate the alternative $a_{1}$ in the set of alternatives A (Tab. 8).

Table 8 Output and input flow value

\begin{tabular}{|c|c|c|c|c|c|}
\hline & $a_{1}$ & $a_{2}$ & $a_{3}$ & $a_{4}$ & $\Phi^{+}\left(a_{i}\right)$ \\
\hline$a_{1}$ & 0 & $\pi\left(a_{1}, a_{2}\right)$ & $\pi\left(a_{1}, a_{3}\right)$ & $\pi\left(a_{1}, a_{4}\right)$ & $\checkmark$ \\
\hline$a_{2}$ & $\pi\left(a_{2}, a_{1}\right)$ & 0 & $\pi\left(a_{2}, a_{3}\right)$ & $\pi\left(a_{2}, a_{4}\right)$ & $\checkmark$ \\
\hline$a_{3}$ & $\pi\left(a_{3}, a_{1}\right)$ & $\pi\left(a_{3}, a_{2}\right)$ & 0 & $\pi\left(a_{3}, a_{4}\right)$ & $\checkmark$ \\
\hline$a_{4}$ & $\pi\left(a_{4}, a_{1}\right)$ & $\pi\left(a_{4}, a_{2}\right)$ & $\pi\left(a_{4}, a_{3}\right)$ & 0 & $\checkmark$ \\
\hline$\Phi^{-}\left(a_{i}\right)$ & $\checkmark$ & $\checkmark$ & $\checkmark$ & $\checkmark$ & \\
\hline
\end{tabular}

$5^{\text {th }}$ Step - The computation of the net flow values for all the alternatives according to Eq. (5) below and the complete ranking of alternatives (PROMETHEE 2).

$$
\Phi\left(a_{i}\right)=\Phi^{+}\left(a_{i}\right)-\Phi^{-}\left(a_{i}\right)
$$

\section{EXPERIMENT-NOISE MONITORING \\ 4.1 Measurement Point Description and Characteristics}

For the purpose of this research, a continuous noise measurement for road traffic was performed at the measurement point MP in the city of Niš, Serbia.

The reasons for choosing this location include the following:

- Heavy road traffic during the day/evening (ca. 1200 vehicles/h) and during the night (ca. 600 vehicles/h) [19]; - A complex structure of the road traffic: motorcycles, automobiles, light commercial vehicles, heavy goods vehicles, buses, and coaches;

- Flat terrain (zero road inclination). 


\subsection{Measuring Equipment Description and Characteristics}

Brüel \& Kjær Environmental Noise Management System (ENMS), designed for long-term environmental noise monitoring, was used to measure road traffic noise at the measurement point MP. Primary elements of the system include Software Type 7843 and the Noise Monitoring Terminal type 3639-B-203. To monitor weather conditions during noise measurement, the system was additionally equipped with the Vaisala Weather Transmitter WXT 520, designed to measure air temperature and relative humidity, atmospheric pressure, wind speed and direction, and the amount of precipitation.

The long-term monitoring of road traffic noise was completed in accordance with the guidelines provided in the standard [2] and the EU documents [20, 21].

\subsection{Results of Noise Monitoring}

Continuous noise monitoring at the measurement point MP was performed from 1 September 2017 to 31 August 2018 , providing the data on weekly, monthly, semi-annual, and annual ANI values. The results of the monitoring in $\mathrm{dB}$ are given in Tab. 9 to Tab. 12.

Table 9 Weekly reports (Monday to Sunday)

\begin{tabular}{|c|c|c|c|c|}
\hline & $L_{\text {day }}$ & $L_{\text {evening }}$ & $L_{\text {night }}$ & $L_{\text {den }}$ \\
\hline average & 68.8 & 68.2 & 64.2 & 72.1 \\
\hline stdev & 0.62 & 0.54 & 0.43 & 0.46 \\
\hline $\max$ & 70.3 & 69.7 & 65.3 & 73.4 \\
\hline $\min$ & 67.7 & 67.2 & 63.3 & 71.2 \\
\hline$\left|\Delta L_{\max }\right|$ & 1.5 & 1.5 & 1.1 & 1.3 \\
\hline
\end{tabular}

Table 10 Monthly reports (September 2017 to August 2018)

\begin{tabular}{|c|c|c|c|c|}
\hline & $L_{\text {day }}$ & $L_{\text {evening }}$ & $L_{\text {night }}$ & $L_{\text {den }}$ \\
\hline average & 68.8 & 68.2 & 64.2 & 72.1 \\
\hline stdev & 0.55 & 0.46 & 0.31 & 0.37 \\
\hline $\max$ & 69.6 & 69.2 & 64.9 & 72.8 \\
\hline $\min$ & 68.0 & 67.5 & 63.8 & 71.6 \\
\hline$\left|\Delta L_{\max }\right|$ & 0.8 & 1.0 & 0.7 & 0.7 \\
\hline
\end{tabular}

Table 11 Semi-annual reports 1 (September to February) and 2 (March to August)

\begin{tabular}{|c|c|c|c|c|}
\multicolumn{5}{|c|}{ August) } \\
\hline 1 & $L_{\text {day }}$ & $L_{\text {evening }}$ & $L_{\text {night }}$ & $L_{\text {den }}$ \\
\hline 2 & 69.2 & 68.5 & 64.4 & 72.3 \\
\hline average & 68.4 & 68.0 & 64.1 & 71.8 \\
\hline stdev & 68.8 & 68.2 & 64.2 & 72.1 \\
\hline $\max$ & 0.42 & 0.27 & 0.15 & 0.24 \\
\hline $\min$ & 69.2 & 68.5 & 64.4 & 72.3 \\
\hline$\left|\Delta L_{\max }\right|$ & 68.4 & 68.0 & 64.1 & 71.8 \\
\hline
\end{tabular}

\section{Table 12 Annual report}

\begin{tabular}{|c|c|c|c|}
\hline \multicolumn{5}{|c|}{ Table 12 Annual report } \\
\hline$L_{\text {day }}$ & $L_{\text {evening }}$ & $L_{\text {night }}$ & $L_{\text {den }}$ \\
\hline 68.8 & 68.2 & 64.2 & 72.1 \\
\hline
\end{tabular}

\section{RESEARCH RESULTS AND DISCUSSION}

Visual PROMETHEE software package [22] was used to first choose the optimal measurement strategy for the measurement point MP (scenario 1), after which the type of preference functions and the parameter values for the same criteria values were changed to examine the stability of the solution (scenario 2).

Stricter conditions for the ranking of the alternatives were imposed in scenario 2 , specifically through the selection of a preference function with a linear preference and indifference area and through the adoption of a lower value of the preference parameter compared to scenario 1 .

The following applies to the criteria $f_{1} \div f_{4}$ for scenario 2: if the difference of the standard deviations of measurement results according to the alternatives (stdev) is equal to or higher than $1 \mathrm{~dB}$, there is a strict preference for the alternative with the lower standard deviation; on the other hand, if the difference is less than $0,1 \mathrm{~dB}$, the two compared alternatives are considered indifferent, i.e. of the same importance.

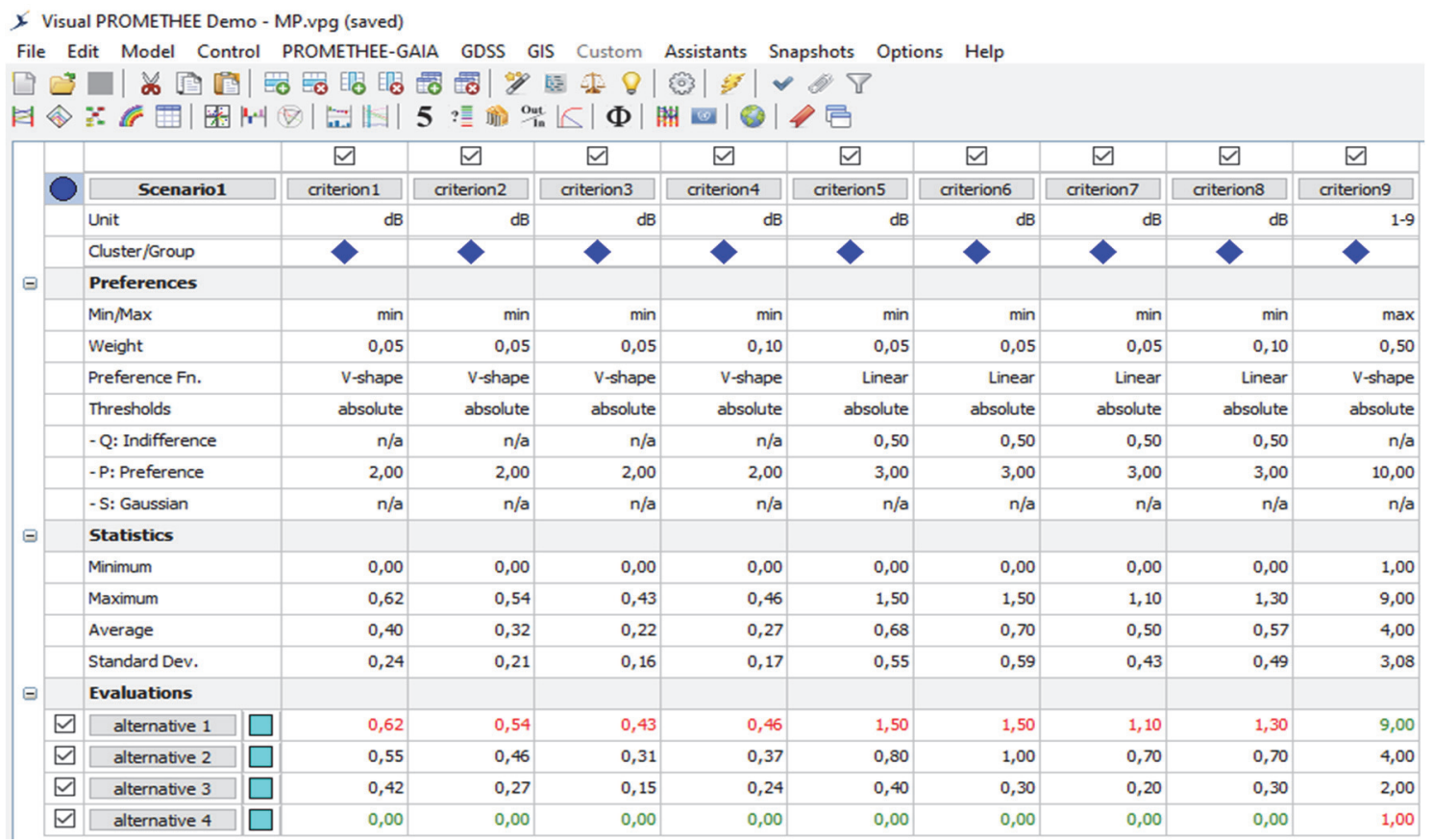

Figure 1 Decision matrix for the measurement point MP-scenario 1 


\begin{tabular}{|c|c|c|c|c|c|c|c|c|c|c|c|c|}
\hline \multicolumn{13}{|c|}{ 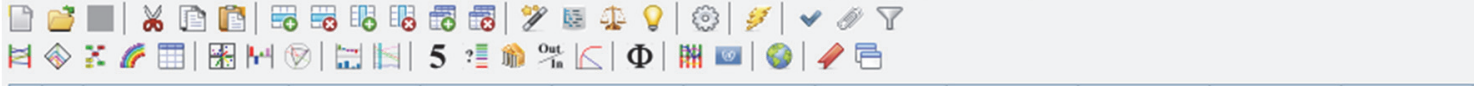 } \\
\hline \multirow{12}{*}{$\Theta$} & & & & $\nabla$ & $\nabla$ & $\nabla$ & 口 & $\nabla$ & $\nabla$ & $\nabla$ & $\nabla$ & $\nabla$ \\
\hline & & Scenario2 & & criterion 1 & criterion2 & criterion3 & criterion4 & criterion5 & criterion6 & criterion7 & criterion8 & criterion9 \\
\hline & & Unit & & $\mathrm{dB}$ & $d B$ & $d B$ & $d B$ & $\mathrm{~dB}$ & dB & $d B$ & $d B$ & $1-9$ \\
\hline & & Cluster/Group & & $>$ & 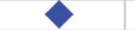 & $>$ & $>$ & $>$ & $>$ & $>$ & $>$ & $>$ \\
\hline & & Preferences & & & & & & & & & & \\
\hline & & Min/Max & & $\min$ & $\min$ & $\min$ & $\min$ & $\min$ & $\min$ & $\min$ & $\min$ & $\max$ \\
\hline & & Weight & & 0,05 & 0,05 & 0,05 & 0,05 & 0,05 & 0,05 & 0,05 & 0,10 & 0,50 \\
\hline & & Preference Fn. & & Linear & Linear & Linear & Linear & Linear & Linear & Linear & Linear & Linear \\
\hline & & Thresholds & & absolute & absolute & absolute & absolute & absolute & absolute & absolute & absolute & absolute \\
\hline & & -Q: Indifference & & 0,10 & 0,10 & 0,10 & 0,10 & 0,50 & 0,50 & 0,50 & 0,50 & 1,00 \\
\hline & & -P: Preference & & 1,00 & 1,00 & 1,00 & 1,00 & 2,00 & 2,00 & 2,00 & 2,00 & 8,00 \\
\hline & & - S: Gaussian & & $\mathrm{n} / \mathrm{a}$ & $n / a$ & $n / a$ & $n / a$ & $n / a$ & $\mathrm{n} / \mathrm{a}$ & $n / a$ & $\mathrm{n} / \mathrm{a}$ & $n / a$ \\
\hline \multirow[t]{5}{*}{$\Theta$} & & Statistics & & & & & & & & & & \\
\hline & & Minimum & & 0,00 & 0,00 & 0,00 & 0,00 & 0,00 & 0,00 & 0,00 & 0,00 & 1,00 \\
\hline & & Maximum & & 0,62 & 0,54 & 0,43 & 0,46 & 1,50 & 1,50 & 1,10 & 1,30 & 9,00 \\
\hline & & Average & & 0,40 & 0,32 & 0,22 & 0,27 & 0,68 & 0,70 & 0,50 & 0,57 & 4,00 \\
\hline & & Standard Dev. & & 0,24 & 0,21 & 0,16 & 0,17 & 0,55 & 0,59 & 0,43 & 0,49 & 3,08 \\
\hline \multirow[t]{5}{*}{$\Theta$} & & Evaluations & & & & & & & & & & \\
\hline & $\square$ & alternative 1 & $\square$ & 0,62 & 0,54 & 0,43 & 0,46 & 1,50 & 1,50 & 1,10 & 1,30 & 9,00 \\
\hline & 口 & alternative 2 & $\square$ & 0,55 & 0,46 & 0,31 & 0,37 & 0,80 & 1,00 & 0,70 & 0,70 & 4,00 \\
\hline & $\square$ & alternative 3 & $\square$ & 0,42 & 0,27 & 0,15 & 0,24 & 0,40 & 0,30 & 0,20 & 0,30 & 2,00 \\
\hline & $\square$ & alternative 4 & $\square$ & 0,00 & 0,00 & 0,00 & 0,00 & 0,00 & 0,00 & 0,00 & 0,00 & 1,00 \\
\hline
\end{tabular}

Figure 2 Decision matrix for the measurement point MP - scenario 2

The following applies to the criteria $f_{5}-f_{8}$ for scenario 2: if the difference of the maximum absolute deviations of the measurement results according to the alternatives $\left(\left|\Delta L_{\max }\right|\right)$ is equal to or higher than $2 \mathrm{~dB}$, there is a strict preference for the alternative with the lower deviation; if the difference is less than $0,5 \mathrm{~dB}$, the two compared alternatives are considered indifferent, i.e. of the same importance.

The main Visual PROMETHEE windows for the problem of choosing the optimal measurement strategy for the measurement point MP based on scenario 1 and scenario 2 are shown in Fig. 1 and Fig. 2.

The PROMETHEE Flow table (Fig. 3) displays the results of the output, input, and net flows of all the alternatives and the resulting complete ranking using the PROMETHEE II method.

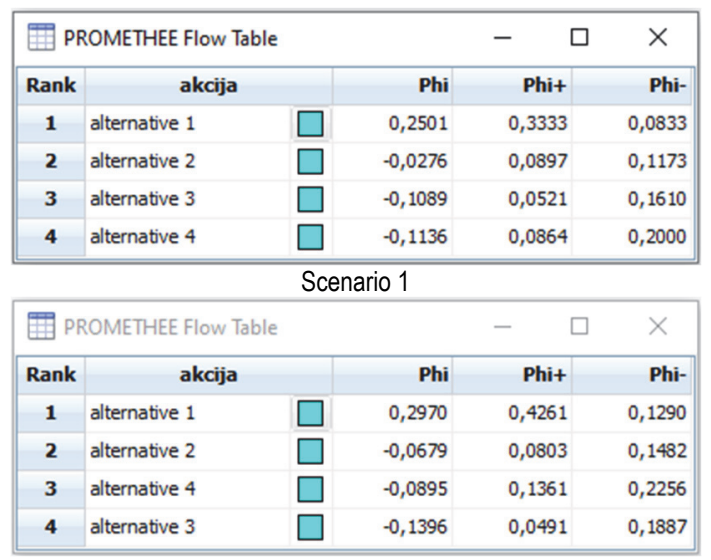

Figure 3 Complete ranking of the alternatives using the PROMETHEE II method for the measurement point MP according to scenarios 1 and 2 and based on the values of net flows of the alternatives

PROMETHEE Rainbow is a particularly suitable way of presenting the results of MCO (Fig. 4), as it provides a disaggregated view of the PROMETHEE II complete ranking. This is a useful way to display the advantages and disadvantages of specific alternatives that were used for their complete ranking.
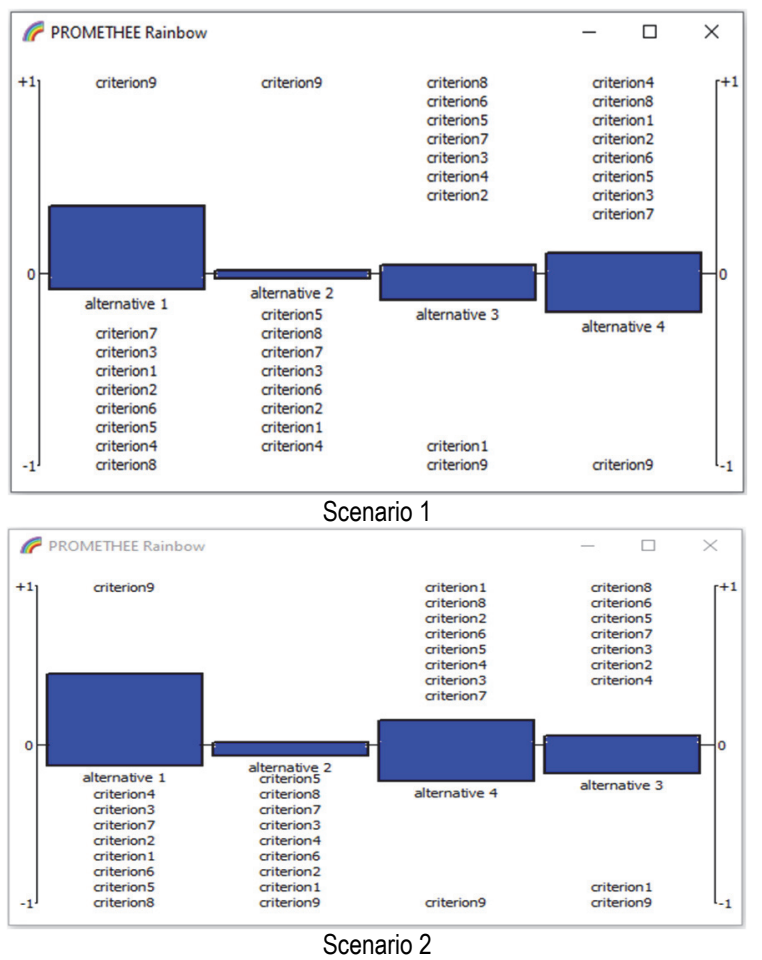

Figure 4 Appearance of the PROMETHEE Rainbow window - alternative ranking for the measurement point MP according to scenarios 1 and 2

The completed procedure for choosing the optimal MTI for the measurement point MP distinguishes the alternative $a_{1}$ (weekly measurement interval) as the most acceptable in terms of the set criteria.

In the case of scenario 1 , the complete alternative comparison is: $a_{1} \rightarrow a_{2} \rightarrow a_{3} \rightarrow a_{4}$. 
Due to the examination of the stability of the solution, in the $2^{\text {nd }}$ scenario, stricter conditions for ranking alternatives were set, after which the following complete order of alternatives was obtained: $a_{1} \rightarrow a_{2} \rightarrow a_{4} \rightarrow a_{3}$.

The solution that has been obtained for the defined conditions fully corresponds to the established goal of investigation to minimize the MTI while obtaining results of satisfactory accuracy and precision, which maximizes the degree of utilization of the measuring equipment.

\section{CONCLUSIONS}

The results obtained using MCO to solve the presented problem led to the following conclusions:

1. Multi-criteria optimization is a useful tool for making decisions on the minimum MTI for noise indicators based on the set criteria and limitations. In addition, it enables the highest possible degree of utilization of the available measuring equipment.

The choice of the optimal solution was influenced by the very selection of MCO due to its sensitivity to the set criteria and expected outcomes, as well as by the subjective opinion of the researchers, which is an inevitable occurrence in multi-criteria decision making, expressed through a personal attitude and a preference for specific alternatives.

The use of the PROMETHEE method in the multicriteria analysis of the available base of experimental data, with its ability to define the conditions and parameters that additionally influence the choice of the optimal measurement strategy, is an entirely acceptable solution in terms of the set research aims and the expected results.

Objectivity was ensured with independent opinions of a panel of experts in the field, who were surveyed regarding the importance of specific criteria for the given problem.

2. The choice of a measurement strategy using a one week long MTI confirms the assumption that a 365 days shorter MTI can indeed provide information on noise indicator values that do not significantly deviate from the true values and remain within the defined limits for accuracy $(1,5 \mathrm{~dB})$ and precision $(1 \mathrm{~dB})$.

3. The measurement strategy that evaluates ANI values with a weekly measurement interval, which was singled out as the optimal solution in this research, applies to the "noisy" urban locations with a traffic volume of 1,000+ vehicles per hour, where road traffic noise is the dominant source of environmental noise.

4. The weather conditions during the long-term noise monitoring, with relatively mild variations, did not influence the values of noise indicators, which means that any week during a year can be selected to perform the measurement.

5. However, the selection of a week in which to perform the measurement is partially restricted due to various holidays or planned events at the measurement location, during which increased acoustic activity is to be expected.

\section{Acknowledgements}

This research is conducted under the auspices of the Ministry of Education, Science and Technological Development of the Republic of Serbia.

\section{REFERENCES}

[1] Directive, EU. (2002). Directive 2002/49/EC of the European parliament and the Council of 25 June 2002 relating to the assessment and management of environmental noise. Official Journal of the European Communities, L, 189(18.07), 2002.

https://eur-lex.europa.eu/legal-content /EN/TXT/PDF/?uri=CELEX:32002L0049\& from=EN

[2] International Organization for Standardization. (2017).Acoustics-Description, measurement and assessment of environmental noise-Part 2: Determination of sound pressure levels (ISO Standard No. 1996-2:2017).

[3] Zylka, L., Burek, J., \& Mazur, D. (2017). Diagnostic of peripheral longitudinal grinding by using acoustic emission signal. Advances in Production Engineering \& Management, 12(3), 221-232. https://doi.org/10.14743/apem2017.3.253

[4] Tang, Z. P., Chen, Z. X., Sun, J. P., Hu, Y. T., \& Zhao M. (2019). Noise Prediction of Traction Gear in High-Speed Electric Multiple Unit. Int. Journal of Simulation Modelling, 18(4), 720-731. https://doi.org/10.2507//JSIMM18(4)CO20

[5] Abbaspour, M., Golmohammadi, R., Nassiri, P., \& Mahjub, H. (2006). Aninvestigation on time-interval optimisation of traffic noise measurement. Journal of low frequency noise, vibration and active control, 25(4), 267-273. https://doi.org/10.1260/026309206779884883

[6] Stančerić, I., Dragčević, V., \& Ahac, S. (2010). Toward environmental noise estimation according to the road surface characteristics and traffic volume. Technical Gazette, 17(2), 191-197.

[7] Ehrampoush, M. H., Halvani, G. H., Barkhordari, A., \& Zare, M. (2012). Noise Pollution in Urban Environments: a Study in Yazd City, Iran. Polish Journal of Environmental Studies, 21(4), 1095-1100.

[8] Alam, P., Ahmad, K., Afsar, S. S., \& Akhtar, N. (2020) Noise Monitoring, Mapping, and Modelling Studies-A Review. Journal of Ecological Engineering, 21(4), 82-93. https://doi.org/10.12911/22998993/119804

[9] Mihajlov, D. I. \& Prascevic, M. R. (2015). Permanent and semi-permanent road traffic noise monitoring in the city of Nis (Serbia). Journal of low frequency noise, vibration and active control, 34(3), 251-268. https://doi.org/10.1260/0263-0923.34.3.251

[10] Praščević, M., Mihajlov, D., \& Cvetković, D. (2014). Permanent and semi-permanent noise monitoring-first results in the city of Nis. InProceedings of 24th International Conference "Noise and Vibration". 33-40.

[11] Ruiz-Padillo, A., Ruiz, D. P., Torija, A. J., \& Ramos-Ridao, Á. (2016). Selection of suitable alternatives to reduce the environmental impact of road traffic noise using a fuzzy multi-criteria decision model. Environmental Impact Assessment Review, 61, 8-18. https://doi.org/10.1016/j.eiar.2016.06.003

[12] Nikolić, I., \& Borović, S. (1996). Višekriterijumska optimizacija (Multi-criteria Optimization). Medijacentar Odbrana, Beograd (In Serbian).

[13] Satty, T. L. (1980). The analytic hierarchy process. McGrawHill, New York

[14] Hsu, C. C. \& Sandford, B. A. (2007). The Delphi technique: making sense of consensus. Practical Assessment, Research, and Evaluation, 12(1), 10. https://doi.org/10.7275/pdz9-th90

[15] Hirschhorn, F. (2019). Reflections on the application of the Delphi method: lessons from a case in public transport research. International Journal of Social Research Methodology, 22(3), 309-322. https://doi.org/10.1080/13645579.2018.1543841

[16] Oglu, S. V. H. (2020). Solution of a multi-criteria decisionmaking problem on base of promethee method. International Academy Journal Web of Scholar, 7(49). 
https://doi.org/10.31435/rsglobal_wos/30092020/7182

[17] Brans, J. P. \& De Smet, Y. (2016). PROMETHEE Methods. In: Greco S., Ehrgott M., Figueira J. (eds) Multiple Criteria Decision Analysis. International Series in Operations Research \& Management Science, 233, 187219, Springer, New York, NY. https://doi.org/10.1007/978-1-4939-3094-4_6

[18] Mihajlov, D., Praščević, M., \& Herisanu, N. (2018). Selection of measurement strategy for the assessment of long-term environmental noise indicators using multicriteria optimization. InAcoustics and Vibration of Mechanical Structures-AVMS-2017, 77-82. Springer, Cham. https://doi.org/10.1007/978-3-319-69823-6_9

[19] COWI d.o.o. Belgrade (2010). Study of checking the capacity of the traffic network of the city of Niš for the development of the General Plan of City of Niš. Book 1: Research of the characteristics of traffic flows.

[20] Directive, EU. (2015).Commission Directive (EU) 2015/996 of 19 May 2015 establishing common noise assessment methods according to Directive 2002/49/EC of the European Parliament and of the Council.Official Journal of the European Union, L, 168(01.07), 2015. https://eur-lex.europa.eu/legal-content/EN/TXT/PDF/?uri= CELEX:32015L0996\&from $=\mathrm{EN}$

[21] De Leon, G., Fidecaro, F., Cerchiai, M., Reggiani, M., Ascari, E., \& Licitra, G. (2019).Implementation of CNOSSOS-EU method for road noise in Italy. Universitätsbibliothek der RWTH Aachen.

[22] See http://www.promethee-gaia.net/software.html.

\section{Contact information:}

Darko MIHAJLOV, PhD, ass. prof.

(Corresponding author)

University of Niš,

Faculty of Occupational Safety,

Čarnojevića 10a, 18000 Niš, Serbia

E-mail: darko.mihajlov@znrfak.ni.ac.rs

Momir PRAŠČEVIĆ, PhD, full prof.

University of Niš,

Faculty of Occupational Safety in Niš,

Čarnojevića 10a, 18000 Niš, Serbia

E-mail: momir.prascevic@znrfak.ni.ac.rs

Marko LIČANIN, MSc, teaching assistant

University of Niš,

Faculty of Occupational Safety in Niš,

Carnojevića 10a, 18000 Niš, Serbia

E-mail: marko.licanin@znrfak.ni.ac.rs

\section{Miomir RAOS, PhD, full prof.}

University of Niš,

Faculty of Occupational Safety in Niš,

Čarnojevića 10a, 18000 Niš, Serbia

E-mail: miomir.raos@znrfak.ni.ac.rs

Branko RADIČEVIĆ, PhD, ass. prof.

University of Kragujevac,

Faculty of Mechanical and Civil Engineering in Kraljevo,

Dositejeva 19, 36000 Kraljevo, Serbia

E-mail: radicevic.b@mfkv.kg.ac.rs 